\title{
To Publish or Not Publish - An Introspective
}

\section{Catarina Lavrador*}

School of Science and Technology (ECT), University of Évora, Portugal

\section{Opinion}

That is truly the question that today arises. The academic world is nowadays profoundly and, I dare say, perversely affected by the pressure to publish. It does not matter if you are a competent, knowledgeable, enthusiastic or even empathetic professor. I believe that these characteristics count almost for nothing. I constantly feel as in the academic world where I navigate, the only requirements are the number of papers we publish every year and the impact factor of the journals where they are published. As I am in the field of veterinary medicine, I am tempted to use the analogy of the pork-processing unit where throughout the assembly line we are fed with supposedly publishable data (not always 100\% accurate nor reliable) and which ultimately produces not sausages but papers. I also have the impression that not even "real" books are considered anymore. I feel overwhelmed and unable to receive students, listen to what they have to say, actively participate in their education as we were supposed to do as professors. Students and the ability to thoroughly teach them what we know, both as scientists and as humans, should be the engine to move us around and to do research and not the other way round. I think as if we have excluded ourselves from the real world. There is a lack of interaction with the society. Our own personal life does not count much either. If you give birth and consciously raise your country's future citizens, if you are a philanthropist, if you are an active member of your own community........... Who cares about that? This situation not only astonishes me but most particularly demoralizes me, sometimes even making me have doubts whether this is indeed the right path for me. Curiously enough this was not always the case. I remember entering the academic world back in 1998 although young but no longer a student, the overall atmosphere was of an immense, almost uncontrollable. We did some research but the aim was also to share it with colleagues and students, in a more applicable approach. The excitement was so intense that often I would feel as if I would still belong to the students' group and could, at any time, become one of them again. The truth is that through the years the enthusiasm has diminished, the inner light that attracted me so much at the beginning also grew dimmer. This is definitely not because of the students - they are still what makes the teaching profession a priceless and unique way of living - but in part to what we are forced to comply in terms of academic research. To conclude there is no time today to be a good professor, just an unhappy one struggling to survive within these two demanding areas. I wish I was able to change this course of events and while building up what I love doing, teaching and being responsible for the implementation of a more translational interaction between science and society. Make no mistake, students are the ones that truly drive us to continue our search for excellence and we should always keep this in mind. *Corresponding author: Catarina Lavrador, DVM. PhD, Assistant Professor,
Institute of Mediterranean Agricultural and Environmental Science (ICAAM); School of
Science and Technology (ECT), University of Évora, Portugal, Tel: 351266740 800;
E-mail: clavrador@uevora.pt

Received October 30, 2015; Accepted November 02, 2015; Published November 05, 2015

Citation: Lavrador C (2015) To Publish or not Publish - An Introspective. J Depress Anxiety S3: 006. doi: 10.4172/2167-1044.S3-006

Copyright: ( 2015 Lavrador C. This is an open-access article distributed under the terms of the Creative Commons Attribution License, which permits unrestricted use, distribution, and reproduction in any medium, provided the original author and source are credited. 